\title{
Ozone loss derived from balloon-borne tracer measurements in the 1999/2000 Arctic winter
}

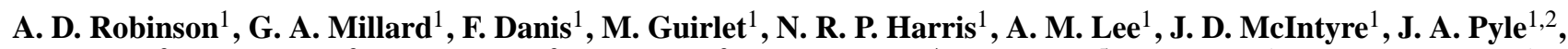 \\ J. Arvelius ${ }^{3}$, S. Dagnesjo ${ }^{3}$, S. Kirkwood ${ }^{3}$, H. Nilsson ${ }^{3}$, D. W. Toohey ${ }^{4}$, T. Deshler ${ }^{5}$, F. Goutail ${ }^{6}$, J.-P. Pommereau ${ }^{6}$,

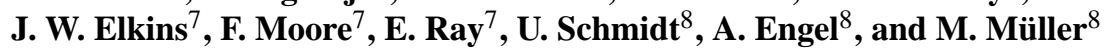 \\ ${ }^{1}$ Centre for Atmospheric Science, Department of Chemistry, Cambridge University, Cambridge CB2 1EW, UK \\ ${ }^{2}$ NCAS-ACMSU, Department of Chemistry, Cambridge University, Cambridge CB2 1EW, UK \\ ${ }^{3}$ Swedish Institute of Space Physics (IRF), Kiruna Division, Box 812, SE-981 28 Kiruna, Sweden \\ ${ }^{4}$ Program in Atmospheric and Oceanic Sciences, 311 UCB, University of Colorado, Boulder, CO 80309-0311, USA \\ ${ }^{5}$ Department of Atmospheric Science, University of Wyoming, P.O. Box 3038, Laramie, WY 82071, USA \\ ${ }^{6}$ Service d'Aeronomie, CNRS, Verrières le Buisson, France \\ ${ }^{7}$ Climate Monitoring and Diagnostics Laboratory, NOAA, Boulder, Colorado, USA \\ ${ }^{8}$ Univ. of Frankfurt, Institut für Atmosphäre und Umwelt, Georg Voigt Str. 14/Robert Mayer Str. 1, 60325 Frankfurt, Germany
}

Received: 16 August 2004 - Published in Atmos. Chem. Phys. Discuss.: 3 November 2004

Revised: 10 May 2005 - Accepted: 12 May 2005 - Published: 14 June 2005

\begin{abstract}
Balloon-borne measurements of CFC11 (from the DIRAC in situ gas chromatograph and the DESCARTES grab sampler), $\mathrm{ClO}$ and $\mathrm{O}_{3}$ were made during the 1999/2000 Arctic winter as part of the SOLVE-THESEO 2000 campaign, based in Kiruna (Sweden). Here we present the CFC11 data from nine flights and compare them first with data from other instruments which flew during the campaign and then with the vertical distributions calculated by the SLIMCAT 3D CTM. We calculate ozone loss inside the Arctic vortex between late January and early March using the relation between $\mathrm{CFC} 11$ and $\mathrm{O}_{3}$ measured on the flights. The peak ozone loss $(\sim 1200 \mathrm{ppbv})$ occurs in the $440-470 \mathrm{~K}$ region in early March in reasonable agreement with other published empirical estimates. There is also a good agreement between ozone losses derived from three balloon tracer data sets used here. The magnitude and vertical distribution of the loss derived from the measurements is in good agreement with the loss calculated from SLIMCAT over Kiruna for the same days.
\end{abstract}

\section{Introduction}

Measurements of long-lived tracers such as $\mathrm{N}_{2} \mathrm{O}, \mathrm{CH}_{4}$ and CFC11 can be used to study a number of aspects of stratospheric transport and chemistry. In the Arctic region, these

Correspondence to: A. D. Robinson

(adr22@cam.ac.uk) include the descent of air in the polar vortices (Schoeberl et al., 1990; Bauer et al., 1994) and mixing processes both at the vortex edge (Waugh et al., 1997; Pyle et al., 1994) and in the lowermost stratosphere (Bregman et al., 2000). Further, changes in the observed compact relations between long-lived tracers and ozone have been used to estimate the magnitude of chemical ozone loss in the Arctic vortex (Proffitt et al., 1990, 1993; Müller et al., 2001 and references therein); this technique is used here with data from two new in situ instruments. Other studies of ozone loss use different techniques (Rex et al., 1999; Goutail et al., 1999; Manney et al., 1997; Knudsen et al., 1998; Lucic et al., 1999 and references therein). Brief descriptions of these techniques, including the tracer relation approach, can be found in Harris et al. (2002), together with a comparison of some of their results. A discussion of the results obtained in this study with other estimates of ozone loss in the 1999/2000 winter is presented in Sect. 5.

In situ measurements of tracers have often involved large grab samplers which can be flown only infrequently. In response to this limitation two new lightweight instruments have been developed by the University of Cambridge to measure CFCs: the in situ GC instrument DIRAC (Robinson et al., 2000) and the grab sampling instrument DESCARTES (Danis et al., 2000). These instruments are easy to operate and can be flown frequently on small, inexpensive balloons as part of a co-ordinated payload. The instruments were flown on several occasions into the vortex core

(C) 2005 Author(s). This work is licensed under a Creative Commons License. 
Table 1. Balloon flights in the 1999/2000 winter from Esrange, Kiruna (67.9 N, 21.1 E) which carried the DIRAC/DESCARTES instruments featured in this work.

\begin{tabular}{llll}
\hline Date & Launch hour (UTC) & Guest instrument & Host payload \\
\hline 3 Dec 1999 & 10 & DESCARTES & OMS remote $^{*}$ \\
15 Dec 1999 & 11 & DESCARTES & SKERRIES \\
19 Jan 2000 & 11 & DIRAC & HALOZ $(C 1 O)^{*}$ \\
27 Jan 2000 & 12 & DIRAC & HALOZ $(C 1 O)^{*}$ \\
28 Jan 2000 & 11 & DESCARTES & SAOZ $^{\dagger}$ \\
1 Mar 2000 & 10 & DESCARTES & HALOZ $(C l O)^{*}$ \\
5 Mar 2000 & 15 & DIRAC, DESCARTES & OMS in situ $^{*}$ \\
7 Mar 2000 & 14 & DESCARTES & SAOZ $^{\dagger}$ \\
8 Mar 2000 & 12 & DIRAC & HALOZ $(C 1 O)^{*}$ \\
\hline
\end{tabular}

* ECC ozonesonde flown as part of the main payload.

${ }^{\dagger}$ ECC ozonesonde flown soon after the main balloon.

during the SOLVE-THESEO 1999/2000 campaign (Newman et al., 2002) with other lightweight instruments including the SAOZ experiment (Pommereau and Piquard, 1994) or as part of the HALOZ project to measure $\mathrm{ClO}$ and related species (Vömel et al., 2001). In this paper we present results from nine balloon flights of these instruments made during SOLVE-THESEO 2000: four flights of the DIRAC in situ gas chromatograph and five flights of the DESCARTES grab sampler.

In the first part of the paper, the instruments and the model are described. The next part presents the measured vertical profiles of CFC11 and ozone (measured by electrochemical concentration cell (ECC) ozonesondes). The vertical profiles are then compared both with data from other instruments which flew during the campaign and to profiles calculated by the SLIMCAT 3D chemical transport model (CTM), used to study ozone loss in previous Arctic winters (e.g. Guirlet et al., 2000). Measurements of $\mathrm{ClO}$ made using a resonance fluorescence instrument (Pierson et al., 1999) on some of the flights are also compared with the $\mathrm{ClO}$ profiles calculated in SLIMCAT (8 Mar 2000 comparison shown here). Changes in the CFC11 and ozone correlations during the winter are then used to make estimates of the ozone loss that occurred in the vortex during 1999/2000. Finally, we compare the measurement based estimates with the ozone loss calculated using the ozone and CFC11 correlations above Kiruna for the same days, as calculated by SLIMCAT, in order to assess the representativeness of the balloon observations.

\section{Measurements}

The measurements featured in this study were made by three instruments flown on balloons from Kiruna during the SOLVE-THESEO 2000 campaign. The balloon flight details are given in Table 1 . The instruments are now briefly described.

\subsection{Halocarbons}

DIRAC (Determination In situ by Rapid Analytical Chromatography) is a lightweight gas chromatograph for use on stratospheric balloons developed by the University of Cambridge. The operation and performance of DIRAC are described by Robinson et al. (2000). The instrument weighed 21 or $24 \mathrm{~kg}$, depending on configuration (although recent instruments with superior performance now weigh $<10 \mathrm{~kg}$ ). A range of halocarbons is detected and can be measured quantitatively. The measurement with the highest precision is CFC11, measured with a time resolution of about $2 \mathrm{~min}$. DIRAC uses a Carboxen adsorbent to preconcentrate samples of known volume before injection onto a separation column and electron capture detector. The accuracy for CFC11 measurements below $400 \mathrm{~K}$, based on the uncertainty of the calibration gas used during the campaign is estimated to be $2.5 \%$. This calibration gas is linked to NOAA-CMDL working standards by comparison to an Aculife treated cylinder containing Niwot Ridge air (calibrated by NOAA-CMDL in July/August 2000). For measurements made at higher altitudes there is a positive instrument bias effect on measurement accuracy which is discussed in the Appendix. The positive bias is low $(<10 \%)$ below $400 \mathrm{~K}$ and rises to around $200 \%$ (factor of 3 higher than reality) at $475 \mathrm{~K}$, where DIRAC reaches its limit of detection for CFC11. All the DIRAC data presented in this work have been corrected for this altitude dependent bias as described in the Appendix.

During SOLVE-THESEO 2000, the in-flight precision using the onboard calibration gas was $0.5 \mathrm{pg}$ of CFC11, taken as the standard deviation of the linear fit (peak area versus mass of CFC11 trapped) to all in-flight calibrations made during the campaign (Fig. 1). No calibrations were performed during ascent but housekeeping data gives us confidence that instrument sensitivity (including desorption efficiency) was constant. For samples taken at low altitudes (be- 
low $400 \mathrm{~K}$ ) where CFC11 mixing ratios are high and sample volumes are large, the precision is typically 5-8 pptv (corresponding to a typical sample mass in the range 10 to $20 \mathrm{pg}$ of CFC11). However, at higher altitudes (above $400 \mathrm{~K}$ ), where both the sample volumes and CFC11 mixing ratios are low, the precision is degraded (at $460 \mathrm{~K}$ the estimated precision is $15-20 \mathrm{pptv}$, corresponding to a sample mass of $1.4 \mathrm{pg}$ of CFC-11). Note that the detection limit of $1 \mathrm{pg}$ of CFC-11 was typically reached at $\sim 475 \mathrm{~K}$ during this campaign. The measurements are analysed here from four flights of DIRAC during SOLVE-THESEO 2000 (Table 1). Three of these (19 Jan, 27 Jan and 8 Mar 2000) were made as part of the HALOZ project (Vömel et al., 2001) and the other was part of the OMS in situ flight (5 Mar 2000). All DIRAC data presented here were taken during the balloon ascent. A fifth DIRAC flight was made in late March, but unfortunately the balloon and payload flew astray over Finland and were not recovered. We have no data for this flight as DIRAC was flying without telemetry.

DESCARTES (Détermination et Séparation par Chromatographie lors de l'Analyse des Résultats des Traceurs Echantillonnés dans la Stratosphère) is a lightweight (17 kg) balloon-borne grab sampling instrument developed by the University of Cambridge in which known volumes of stratospheric air are trapped on sample tubes containing Carboxen. A range of trapped halocarbons is subsequently measured in the laboratory using a gas chromatograph and electron capture detector. For a detailed discussion see Danis et al. (2000). The precision (1 sigma) of the CFC11 measurements made by DESCARTES during this campaign was typically $<15$ pptv for samples taken below $400 \mathrm{~K}$ and typically 5-20 pptv for samples above $400 \mathrm{~K}$. The accuracy is estimated to be about $4 \%$ for CFC11 based on the uncertainty of the calibration gas. All measurements from DESCARTES presented here were analysed by IRF, Kiruna, enabling data to be obtained soon after instrument recovery. A total of 10 DESCARTES flights (including vortex edge flights) were made during the 1999/2000 winter. In this paper, measurements are analysed from the five vortex core flights of the instrument, made with a range of host payloads (Table 1). As with DIRAC, all the DESCARTES CFC11 data presented here were taken during the balloon ascent.

\section{$2.2 \mathrm{ClO}$}

The $\mathrm{ClO}$ measurements used in this paper were made using an instrument based on the technique of chemical conversion/resonance fluorescence (Pierson et al., 1999). The balloon flights were made in the HALOZ project whose aim was to investigate ozone loss in the Arctic winter 1999/2000 (Vömel et al., 2001). A total of five balloon flights of the $\mathrm{ClO}$ instrument were made during the 1999/2000 winter. In this paper, measurements are presented from the HALOZ flight on 8 March 2000 (Table 1).

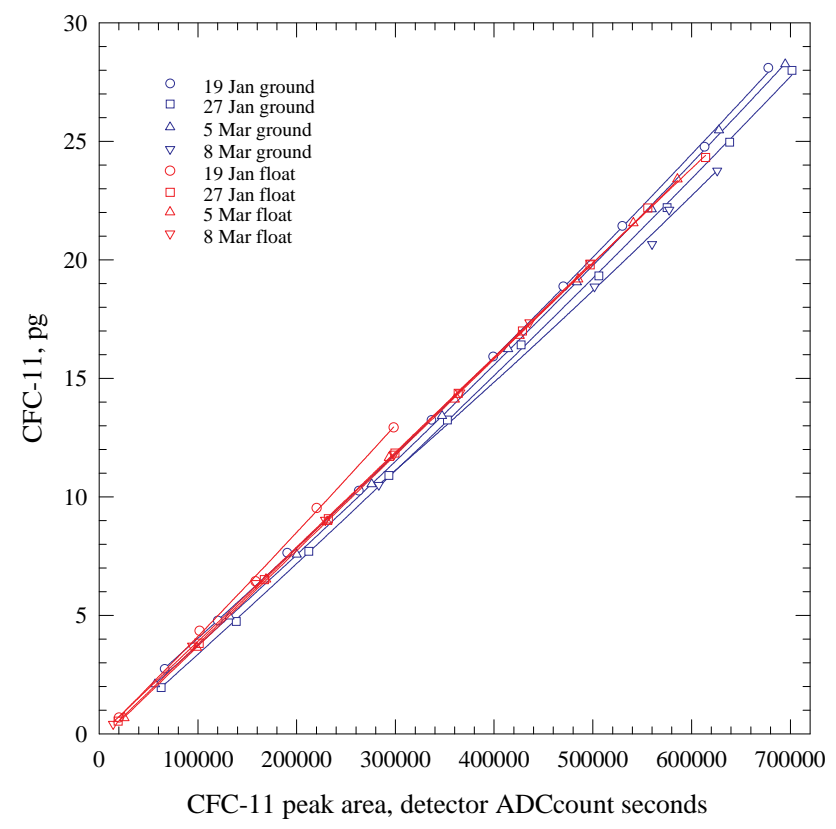

Fig. 1. DIRAC in-flight CFC11 response curves for 19 January, 27 January, 5 March and 8 March used to calibrate the in situ CFC11 measurements. The $\mathrm{x}$-axis is peak area expressed in units of detector ADCcount seconds, the y-axis is mass of CFC-11 measured in the calibration gas, expressed in pg of CFC- 11 .

\subsection{Ozone}

The ozonesonde observations for all the flights used in this study (including those associated with the OMS in situ and Bonbon flights) were made by ECC sondes operated by the University of Wyoming and Esrange.

\section{SLIMCAT 3 dimensional chemical transport model}

The SLIMCAT 3D CTM (Chipperfield et al., 1996; Chipperfield, 1999; Guirlet et al., 2000) is an off-line model driven here with daily U.K. Met. Office winds and temperatures (Swinbank and O'Neill, 1994) on 12 isentropic potential temperature surfaces from $335 \mathrm{~K}$ to $2700 \mathrm{~K}$ at a resolution of $3.75^{\circ}$ latitude by $3.75^{\circ}$ longitude. The model uses the MIDRAD radiation scheme (Shine, 1987) to calculate the cross-isentropic flow and a second-order moments scheme (Prather, 1986) for tracer advection. The Prather scheme has low numerical diffusion and maintains strong gradients in tracer distribution well, an important consideration in polar winter time simulations. A detailed stratospheric chemistry scheme is included in the model with 49 chemical species integrated over a $15 \mathrm{~min}$ timestep. In general, photochemical data are taken from DeMore et al. (1997) and photolysis rates are calculated using a scheme based on Lary and Pyle (1991). The model also contains an equilibrium treatment of reactions on liquid sulphuric acid aerosols and on solid 

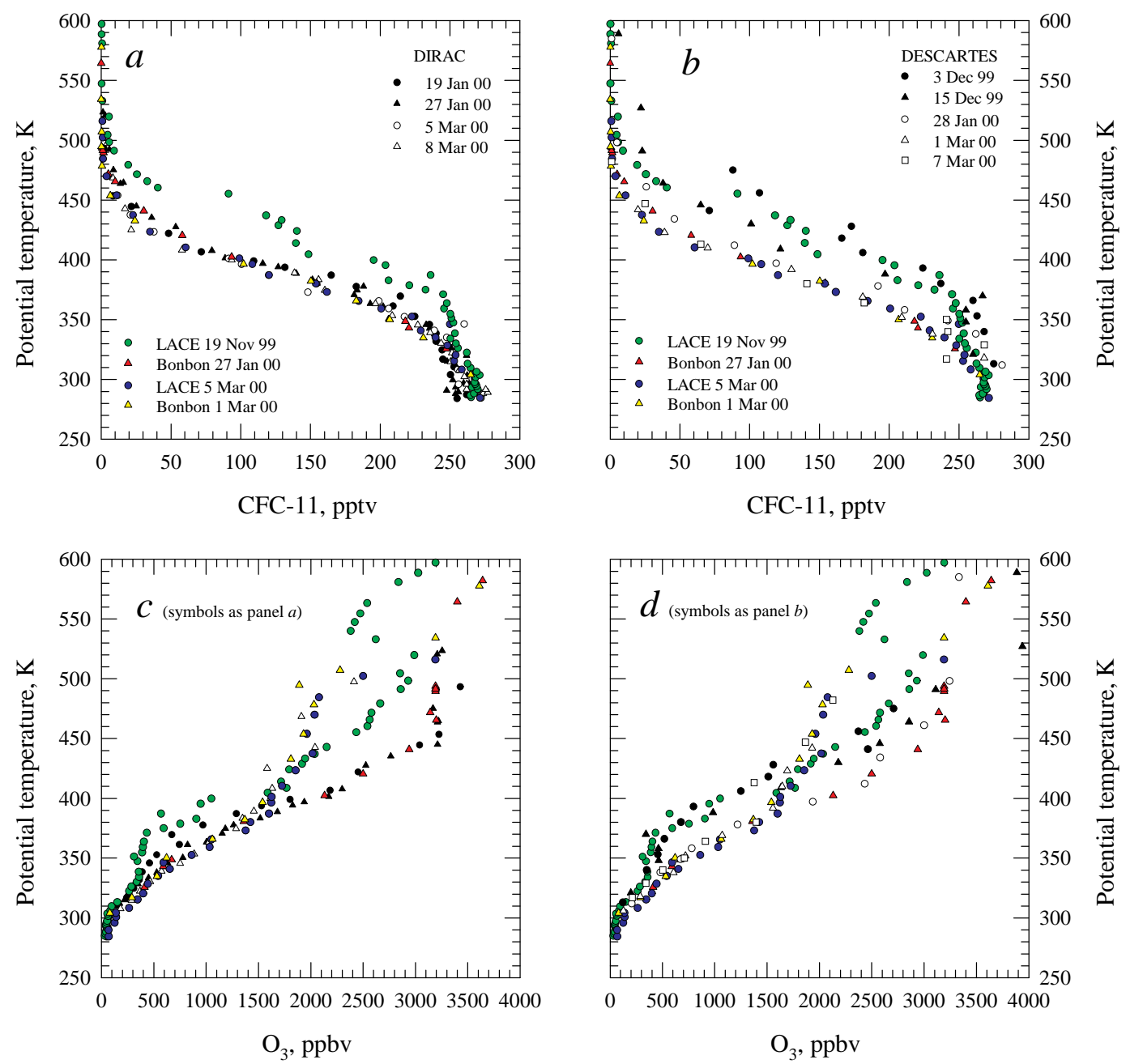

Fig. 2. Vertical profiles of: CFC11 mixing ratio (bias-corrected) from the DIRAC flights (panel $a$ ); CFC11 from the DESCARTES flights (panel $b$ ); ozone mixing ratio from ECC sondes for the DIRAC flights (panel $c$ ); and the DESCARTES flights (panel $d$ ) used as a basis for the ozone loss estimates.

nitric acid trihydrate (NAT) and ice particles. This particular version of the model has been used in studies of Arctic ozone loss in three other cold winters in the late 1990s (Guirlet et al., 2000) and in a detailed comparison to ozone loss rates derived by the Match technique. The winter 1999/2000 simulation was initialised on 30 November 1999 from a low resolution multiannual simulation provided by Chipperfield (1999) with a total chlorine loading of $3.6 \mathrm{ppbv}$ and a total bromine loading of $20 \mathrm{pptv}$. The winter simulation was run until May 2000 with daily output of the chemical fields. Sinnhuber et al. (2000) have already discussed ozone loss in the 1999/2000 winter as calculated by this version of SLIMCAT. The model reproduced observed loss extremely well (see, e.g., a comparison between the model and the observed decline in lower stratospheric ozone at Ny-Ålesund in Fig. 2 from that paper, reproduced as Fig. 3-37 in WMO (2002)) and the model-derived ozone loss is in the centre of the range of estimates discussed in section 3.3.3 of WMO (2002).
Our main purpose in using the model is to give an independent estimate of the 1999/2000 loss against which to compare the loss derived using our data. In addition, we compare the directly calculated model ozone loss with that derived from the model using the CFC-11 vs ozone correlation.

\section{Results}

In the first part of this section the CFC11 vertical profiles from DIRAC and DESCARTES are compared with CFC11 measurements from two other instruments: the Bonbon whole air cryo-sampler (Schmidt et al., 1991) which flew as part of the TRIPLE payload; and the LACE instrument (Ray et al., 1999; Moore et al., 2003) which was part of the NASA-SOLVE OMS in situ payload. The agreement between CFC 11 measured by DIRAC and DESCARTES is also examined for samples above the $360 \mathrm{~K}$ potential temperature 
level (approximating to the lower boundary of the vortex). A change in the relation between $\mathrm{CFC} 11$ and ozone over the winter below this level is unlikely to be the result of chemical ozone loss. A good agreement between the instruments, above the $360 \mathrm{~K}$ potential temperature level, would justify merging the two data sets in order to improve the estimate of ozone loss within the vortex core.

In the second part of this section the measurements from DIRAC and DESCARTES as well as the $\mathrm{ClO}$ and $\mathrm{O}_{3}$ measurements are compared with the output of the SLIMCAT model. This is achieved by making direct comparisons of the measured vertical profiles of $\mathrm{CFC} 11, \mathrm{O}_{3}$ and $\mathrm{ClO}$ with those from the model. In order to make these comparsions, the model vertical profiles are linearly interpolated from model grid points and times to those of the balloon flight track and time.

In the third and last part of this section the relation between measured CFC11 and ozone is compared with the equivalent relation from the model. We also compare the measured $\mathrm{O}_{3} / \mathrm{CFC} 11$ relations from our instruments with those from Bonbon and LACE. Estimates of ozone loss in the vortex can be derived from the change in the measured $\mathrm{O}_{3} / \mathrm{CFC}$ 11 relation through the winter using the approach of Proffitt et al. (1990, 1993) and Müller et al. (2001 and references therein). A compact correlation between two tracers, such as exists between $\mathrm{O}_{3}$ and $\mathrm{CFC} 11$ at the start of the winter, should be maintained if it is assumed that there is no mixing or chemistry operating on the tracers. Changes in the correlation indicate that this assumption is not valid. Within the polar vortex, mixing is usually small and any change in the correlation is most likely due to chemistry. For the specific case of $\mathrm{O}_{3}$ and $\mathrm{CFC} 11$, the chemistry of the latter is very slow with small seasonal changes and the effect of mixing would be small since the relationship between $\mathrm{O}_{3}$ and CFC11 was effectively linear in this winter (Müller et al., 2003) so that changes in the expected correlation can be directly attributed to ozone destruction. Later in this section we use the measurements to estimate ozone loss by this method. Finally, the ozone loss estimates based on the measurements are compared to the losses derived using exactly the same methodology from the change in the $\mathrm{O}_{3} / \mathrm{CFC} 11$ correlations in the model.

\subsection{Measurement comparison}

Here we first compare our CFC11 measurements with those from the Bonbon and LACE instruments and relate them to the vortex situation. Figures $2 \mathrm{a}$ and $\mathrm{b}$ respectively show the vertical profiles of CFC11 from the four DIRAC flights (biascorrected data) and the five DESCARTES flights, together with CFC-11 data from the LACE flights of 19 November and 5 March and the Bonbon flights of 27 January and 1 March. The bias-correction applied to the DIRAC data does not significantly change the data below $400 \mathrm{~K}$. Figures $2 \mathrm{c}$ and $\mathrm{d}$ show the $\mathrm{O}_{3}$ profiles collected for the same flights as depicted in panels a and $\mathrm{b}$ respectively. Potential vorticity (PV) maps from UKMO and the T21 MIMOSA model (Hauchecorne et al., 2002) indicate that the polar vortex between 19 November (LACE flight) and 3 and 15 December (DESCARTES flights) was well formed above $450 \mathrm{~K}$. Below $450 \mathrm{~K}$ it strengthened significantly but is still best classified as a weak vortex. This can explain much of the structure apparent in both $\mathrm{CFC} 11$ and $\mathrm{O}_{3}$ on these flights particularly below $450 \mathrm{~K}$. On the DESCARTES flight of 3 December (Fig. 2b) there was an elongated area of lower PV air above Kiruna at $475 \mathrm{~K}$ which could explain the higher CFC11 values found at this level in the data. Maps of PV from MIMOSA show that all other flights featured here were essentially inside the Arctic vortex over the altitude range sampled (taking the vortex edge to be the zone of maximum PV gradient) and the CFC11 profiles show the expected rapid decrease with altitude. The change in the profiles suggests that considerable descent across potential temperature surfaces occurred throughout the winter, particularly between early December and late January. On 19 January a notch in the DIRAC CFC11 profile at $360 \mathrm{~K}$ (Fig. 2a) is anticorrelated with the $\mathrm{O}_{3}$ profile (Fig. 2c) which suggests a dynamical feature; air at this potential temperature level is likely to be at or below the base of the vortex where such dynamical features are to be expected.

On 27 January DIRAC flew from the same launch site about $2 \mathrm{~h}$ after the Bonbon whole air cryo-sampler. Assuming that the two instruments flew through essentially the same air mass this provided an opportunity for comparison. CFC11 measurements from DIRAC and Bonbon agree well within uncertainty limits, giving confidence in our biascorrection.

There were two occasions during SOLVE-THESEO 2000 on which DESCARTES flew within $24 \mathrm{~h}$ of Bonbon. On 27 January, Bonbon flew first with DESCARTES following $24 \mathrm{~h}$ later and on 1 March Bonbon flew just $5 \mathrm{~h}$ earlier than DESCARTES. All four of these flights were into the vortex core. Examination of the vertical profiles of CFC11 for these flights reveals that the DESCARTES measurements are systematically higher than those from Bonbon at any given altitude. At low altitude ( 300 to $350 \mathrm{~K}$ ) the DESCARTES mixing ratios are typically 20 pptv higher than those from Bonbon and at higher altitude $(>400 \mathrm{~K})$ mixing ratios are typically 10-20 pptv higher than Bonbon. Examination of the $\mathrm{O}_{3} / \mathrm{CFC} 11$ relation for the comparison flights shows that for any given $\mathrm{O}_{3}$ mixing ratio the corresponding DESCARTES CFC11 value is higher than that from Bonbon. However, this difference is within uncertainty limits for high $\mathrm{O}_{3}$ mixing ratios (>2000 ppbv).

To assess the relative agreement between vortex core measurements of CFC11 from DIRAC and DESCARTES we examine the difference in the data for the late January and early March flights when the instruments flew within one or two days of each other (Fig. 3). The differences are based on linear interpolation of the DIRAC CFC11 data to the potential 

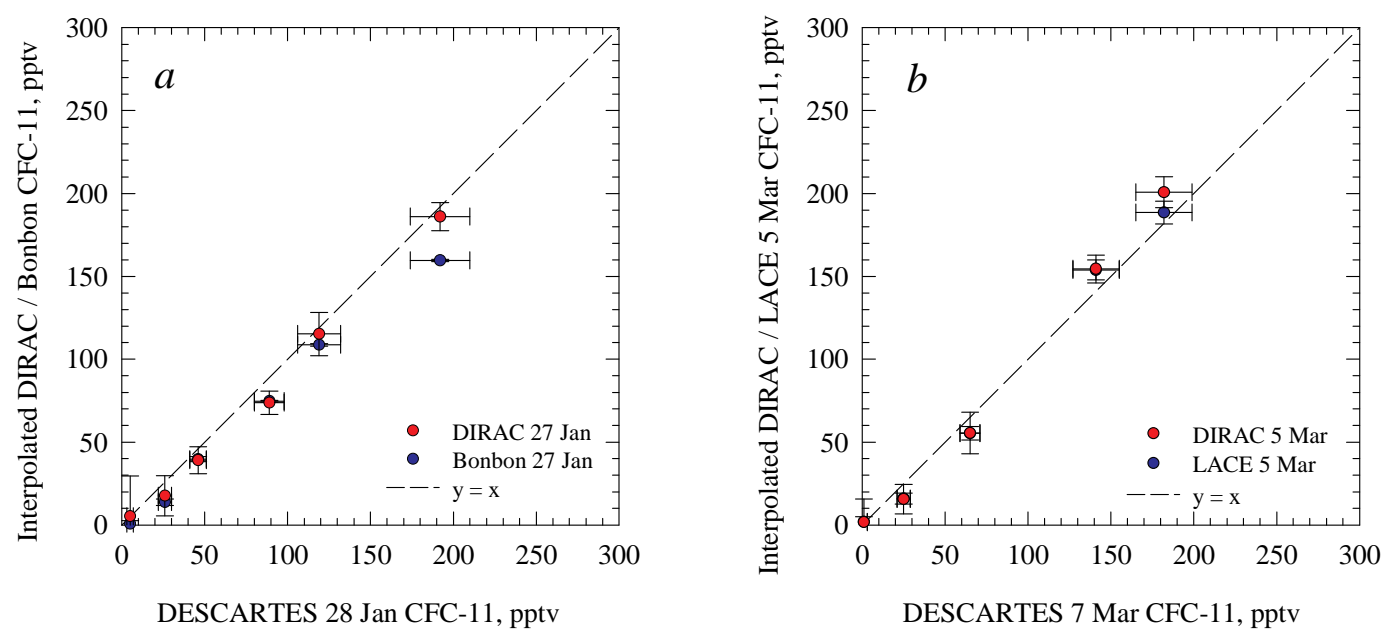

Fig. 3. Plots comparing DIRAC (bias-corrected) and DESCARTES CFC-11 (mixing ratio) measurements from late January (panel $a$ ) and early March (panel $b$ ). The data from both instruments are merged into a single data set on the basis of this agreement for measurements made above $360 \mathrm{~K}$. Bonbon and LACE measurements interpolated to the potential temperature of the DESCARTES measurements are shown for comparison.

temperature levels of the DESCARTES data. Only those data collected above $360 \mathrm{~K}$ are used in the assessment which approximates to the lowermost extent of the vortex circulation system. For both the January and March DIRAC and DESCARTES flight pairs there were only small differences beyond measurement uncertainties between the data points and the line $y=x$ (a 1:1 agreement) and so a merged data set was produced, based on the DIRAC and DESCARTES measurements, to estimate ozone loss using the tracer ozone relation technique.

\subsection{Measurement and model agreement}

Here we compare our measurements of $\mathrm{CFC} 11, \mathrm{O}_{3}$ and $\mathrm{ClO}$ directly with the SLIMCAT model output data. Comparisons between the measured CFC11 profiles and those calculated by the SLIMCAT 3D CTM for the same location and day are shown in Fig. 4. At altitudes below CFC-11 values of 100 pptv (approximately $400 \mathrm{~K}$ ) there is excellent agreement. Above this level, while the broad structure of the profiles are similar, the model values tend to substantially overestimate the observations, presumably due to too weak descent. Note that this does not significantly affect our subsequent analysis. In this region the CFC-11 values are already very low and the vast majority of chlorine is in inorganic forms; an overestimation of CFC-11 will have only a very small impact on the chlorine available for activation (and, hence, on calculated ozone loss). We will also use the model $\mathrm{O}_{3} / \mathrm{CFC}-11$ correlation to calculate ozone loss; overestimation of CFC-11 does not affect how that correlation changes with time and hence does not affect the loss derived in this way. There is also good agreement between $\mathrm{O}_{3}$ measured by the ECC sondes and the $\mathrm{O}_{3}$ calculated in SLIMCAT although the model generally underestimates the amount of ozone during March by about 200 ppbv. On certain flights, structure in the CFC11 measurements, whilst not picked up by the model at this resolution, is seen anticorrelated in the ozonesonde data (e.g. 3 Dec 1999, 27 Jan and 8 Mar 2000) confirming that the instruments are able to capture these dynamical features.

To allow $\mathrm{ClO}$ observations to be compared directly with model calculations at the measurement times, the output from the SLIMCAT simulation of the 1999-2000 northern hemisphere winter (only stored daily at 12:00 UT) was used to initialise a set of stacked photochemical box models. The stacked box models were then integrated over a diurnal cycle for comparison with the observations, following the method used by Solomon et al. (2000). The stacked box models used an identical chemistry scheme to the full 3-D model except that all 49 chemical species in the model were integrated separately with a $1 \mathrm{~min}$ time step; no family or photochemical steady-state assumptions were made.

Figure 5 shows an example of the comparison between the $\mathrm{ClO}$ measurements and results from the $\mathrm{ClO}-\mathrm{Cl}_{2} \mathrm{O}_{2}$ model for 8 March 2000 (we looked also at the 27 January and 1 March 2000 flights and found a similar agreement). There is very good agreement in the low stratosphere below the $\mathrm{ClO}$ maximum both in magnitude and the general shape of the profile. Although the model significantly overestimates the observed $\mathrm{ClO}$ above about $475 \mathrm{~K}$, this region is not a focus of our paper (we note however that Vogel et al. (2003) have also commented on a similar discrepancy between $\mathrm{ClO}$ measurements made on a flight from Kiruna on 1 March 2000 and the ClaMS model above about $500 \mathrm{~K}$ ). The structure at $425 \mathrm{~K}$ in the measurements is not picked up in the model. The analysed temperature fields do, however, indicate that air masses at this altitude had been recently processed on PSCs but this feature is between two model levels at $400 \mathrm{~K}$ and $450 \mathrm{~K}$. 


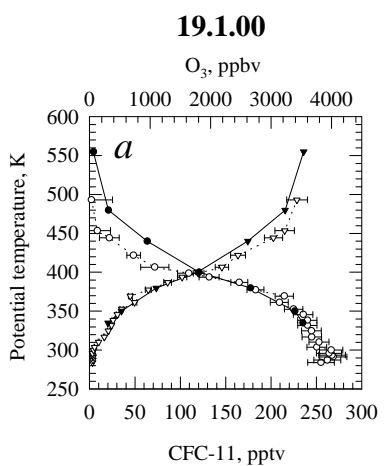

3.12.99

$\mathrm{O}_{3}$, ppbv

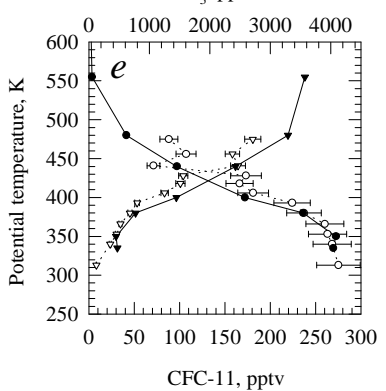

27.1.00

$\mathrm{O}_{3}, \mathrm{ppbv}$

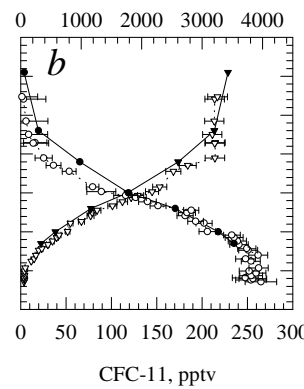

15.12.99

$\mathrm{O}_{3}, \mathrm{ppbv}$

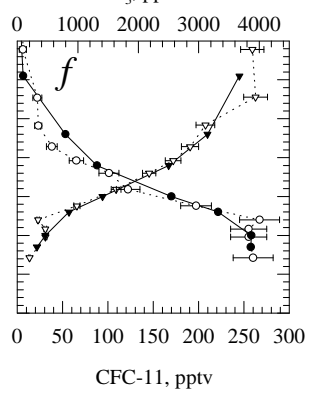

5.3.00

$\mathrm{O}_{3}, \mathrm{ppbv}$

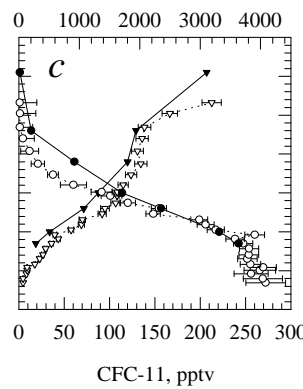

28.1.00

$\mathrm{O}_{3}, \mathrm{ppbv}$

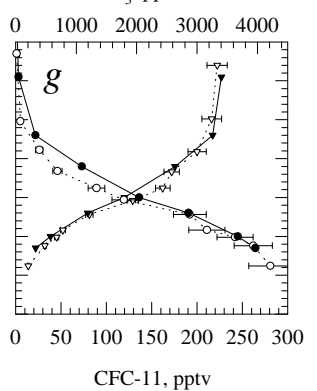

8.3.00

$\mathrm{O}_{3}$, ppbv

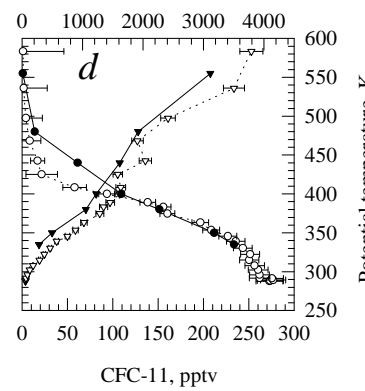

1.3.00

$\mathrm{O}_{3}$, ppbv

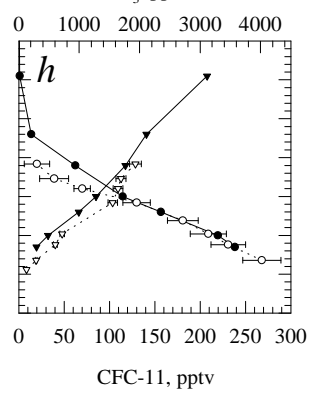

…… CFC-11 measurement

- CFC-11 SLIMCAT

$\rightarrow \cdots \mathrm{O}_{3}$ measurement

$\longrightarrow \mathrm{O}_{3}$ SLIMCAT

Fig. 4. Comparisons between measured and modelled (SLIMCAT) mixing ratio vertical profiles for CFC11 and ozone (panels $a$ to $d$ : DIRAC flights (bias-corrected); panels $e$ to $i$ : DESCARTES flights).

All the flights considered were inside the polar vortex where the model performance is good; we caution however that there may be regions, especially at the vortex edge, where detailed comparisons between model and observations are less satisfactory.

\subsection{Estimated ozone loss in the vortex}

Chemical ozone loss can be estimated from changes in the relation between the mixing ratios of $\mathrm{O}_{3}$ and a long-lived tracer. In any particular winter, this approach requires that (a) a representative early winter reference can be established; and (b) transport process (e.g. mixing of extra-vortex air into the vortex) do not significantly change the initial relationship. These two points are now discussed in turn.

In late 1999 the Arctic vortex was isolated and well-mixed (Kawa et al., 2002). The only odd feature was a notch of lower ozone around $30 \mathrm{hPa}$ observed during the OMS in situ balloon flight on 19 November, which was attributed as being a dynamical feature which developed during the vortex formation (Salawitch et al., 2002). However, analysis of the available satellite data indicates that ozone variability inside the vortex was low and that this feature was anomalous (Kawa et al., 2002). Accordingly, early winter ozone/tracer relations have been calculated from balloon profiles, whose estimated uncertainties reflect the variability in the $\mathrm{O}_{3}$ /tracer

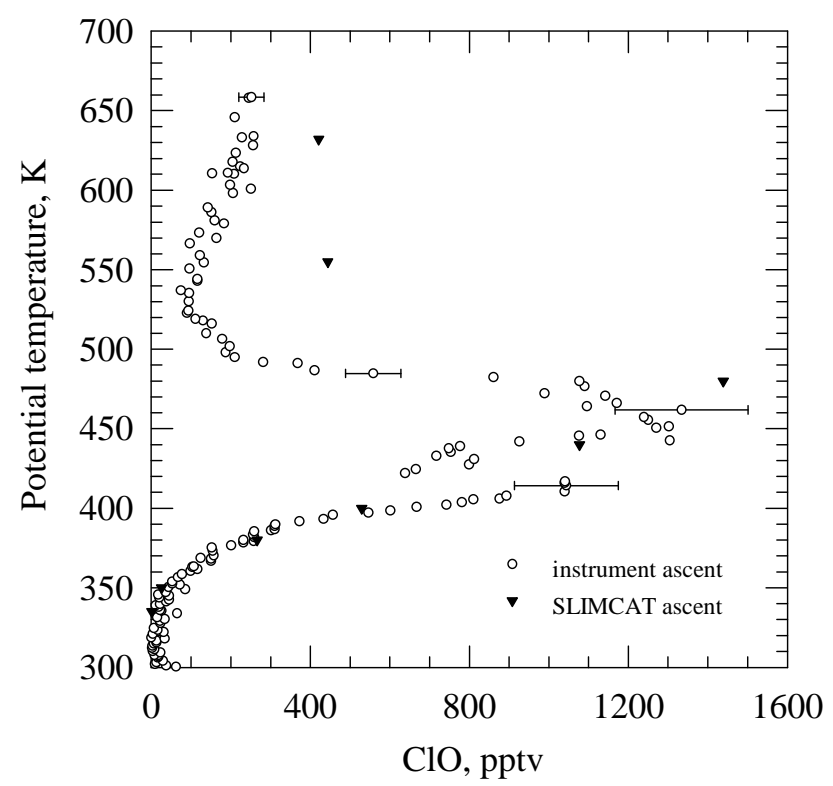

Fig. 5. Comparison between the vertical profile from the $\mathrm{ClO}$ instrument and from SLIMCAT on 8 March. The overall uncertainty of the $\mathrm{ClO}$ instrument data is shown by the error bars ( 1 standard deviation) at selected points in the profile. 
Table 2. Grouped DIRAC and DESCARTES flight ensembles used to examine ozone change from December to January (a) and from January to March (b) in the 1999/2000 Arctic winter.

a: Ozone change: early December to late January

\begin{tabular}{lll}
\hline & December flight ensemble & January flight ensemble \\
\hline Date 1 & DESCARTES 3 Dec 99 & DIRAC 19 Jan 00 \\
Date 2 & DESCARTES 15 Dec 99 & DIRAC 27 Jan 00 \\
Date 3 & & DESCARTES 28 Jan 00 \\
Average date & 9 Dec 99 & 25 Jan 00 \\
\hline
\end{tabular}

b: Ozone change: late January to early March

\begin{tabular}{lll}
\hline & January flight ensemble & March flight ensemble \\
\hline Date 1 & DIRAC 19 Jan 00 & DESCARTES 1 Mar 00 \\
Date 2 & DIRAC 27 Jan 00 & DIRAC 5 Mar 00 \\
Date 3 & DESCARTES 28 Jan 00 & DESCARTES 7 Mar 00 \\
Date 4 & & DIRAC 8 Mar 00 \\
Average date & 25 Jan 00 & 5 Mar 00 \\
\hline
\end{tabular}

relation at that time (Müller et al., 2003; Salawitch et al., 2002).

Salawitch et al. (2002) further conclude that transport processes did not significantly affect the $\mathrm{O}_{3} / \mathrm{N}_{2} \mathrm{O}$ relationship in the vortex core between November 1999 and early March 2000. This finding is supported by the analyses of other tracer data sets in SOLVE-THESEO 2000 that there was little mixing into the vortex between the second half of January and early March 2000 (Rex et al., 2002; Ray et al., 2002; Richard et al., 2001).

Here, we merge the measurements of CFC11 and ozone (for measurements made above $360 \mathrm{~K}$ ) from the DIRAC (bias-corrected CFC-11) and DESCARTES flights and use this merged data set to estimate ozone loss. First, the observed $\mathrm{O}_{3} / \mathrm{CFC} 11$ relations from the merged DIRAC and DESCARTES flights are compared with relations from the Bonbon and LACE flights and also the equivalent relations from the SLIMCAT model. Secondly, these relations, for both the merged measurements and the model, are used to estimate ozone loss as a function of altitude in the vortex for two periods through the winter. Because the data quality and the absolute CFC-11 concentrations decrease with altitude, our analysis of loss is confined to potential temperatures below $480 \mathrm{~K}$.

To examine the changes in the vertical distribution of ozone throughout the winter, flights made within a few days of each other are treated as a merged ensemble (Table 2). CFC11 data for each flight within each ensemble are interpolated to the potential temperature measurement levels of
Table 3. Linear regression parameters $(y=a+b x)$ for the measured (a) and modelled (b) $\mathrm{O}_{3} / \mathrm{CFC}-11$ relations for the merged flight ensembles, where: $\mathrm{x}=\mathrm{CFC}-11$ mixing ratio; $\mathrm{y}=\mathrm{O}_{3}$ mixing ratio.

a: Regression parameters for the measured $\mathrm{O}_{3} / \mathrm{CFC}-11$ relations

\begin{tabular}{lccc}
\hline & $\mathrm{a}$ & $\mathrm{b}$ & $\mathrm{r}^{2}$ \\
\hline early (9) Dec 1999 & 3658 & -13.11 & 0.956 \\
late (25) Jan 2000 & 3272 & -11.65 & 0.991 \\
early (5) Mar 2000 & 2001 & -4.65 & 0.923 \\
\hline
\end{tabular}

b: Regression parameters for the modelled $\mathrm{O}_{3} / \mathrm{CFC}-11$ relations

\begin{tabular}{lccc}
\hline & $\mathrm{a}$ & $\mathrm{b}$ & $\mathrm{r}^{2}$ \\
\hline early (9) Dec 1999 & 3688 & -12.53 & 0.996 \\
late (25) Jan 2000 & 3475 & -12.77 & 0.999 \\
early (5) Mar 2000 & 2122 & -7.21 & 0.998 \\
\hline
\end{tabular}

the later flight of the ensemble. The CFC11 data at each potential temperature level are then averaged to obtain a single CFC11 profile. The uncertainty for each averaged CFC11 measurement is the average of the quadrature addition of the fractional uncertainties of each individual measurement used in that average. An average ozone profile is then generated in exactly the same way as the CFC11 average profile for each ensemble. The date of each averaged ensemble is taken as the average of all the individual flight dates used to generate the ensemble. The ozone change is finally obtained by taking the difference in ozone on equivalent CFC11 levels between paired ensembles.

Figure 6a and Table 3a show the relations between CFC11 and $\mathrm{O}_{3}$ for the merged DIRAC and DESCARTES data between the early December and late January flight ensembles. There is little difference in the relation between the December and January data (average dates 9 Dec and 25 Jan respectively, 47 days separation), suggesting little loss during this period (but see below). Figure 6a also shows the $\mathrm{O}_{3} / \mathrm{CFC}$ 11 relations for the LACE flight on 19 November and the Bonbon flight on 27 January. There is a good agreement between the merged early December data and the LACE November data for all values of ozone apart from the region between 2600 and $3300 \mathrm{ppbv}$ where the LACE data shows lower ozone for a given CFC11 value by up to 500 ppbv.

In contrast to the December to January period, a clear split is seen in the $\mathrm{O}_{3} / \mathrm{CFC} 11$ relations between January and March (average dates 25 Jan and 5 Mar respectively, 39 days separation) as shown by the solid and dashed regression lines in Fig. 6b (and Table 3a). Note that the uncertainty in the relation is large for the high altitude points at the top of the depleted ozone layer as the sample volumes and flow rates here were low and also this region was only sampled by DIRAC. 

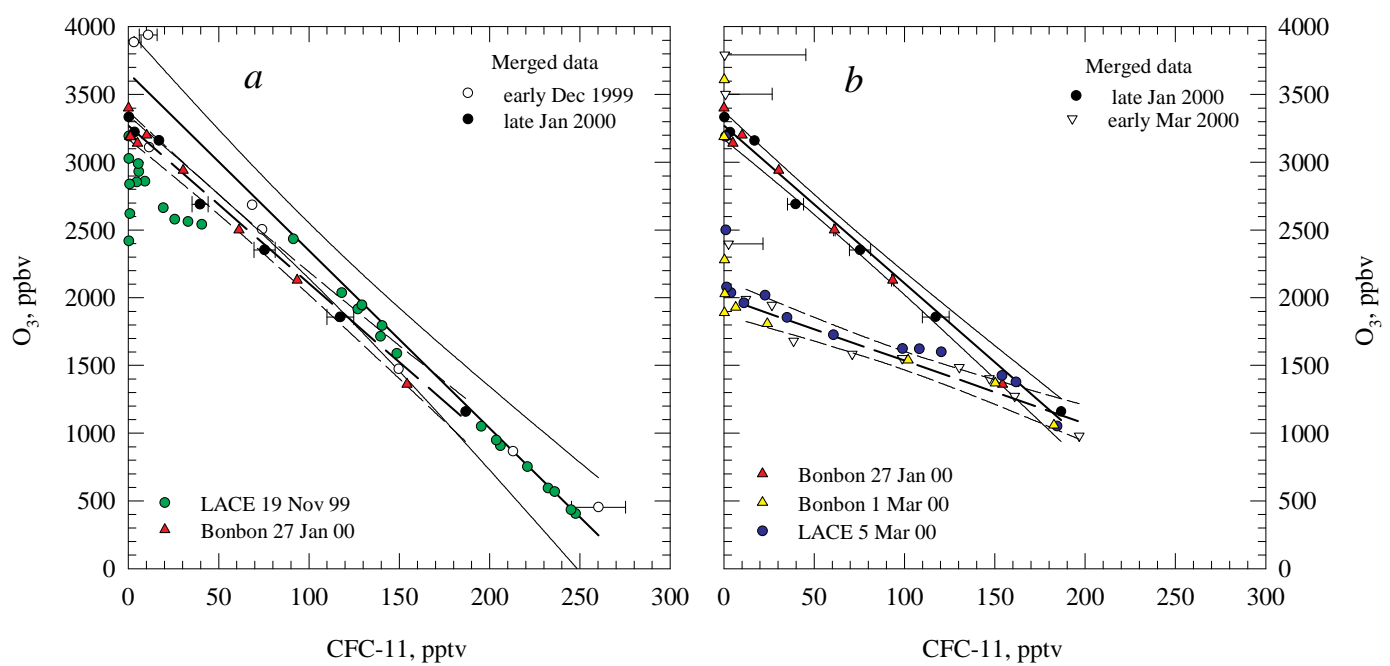

Fig. 6. The relationship between CFC11 and ozone mixing ratios for the DIRAC/DESCARTES (DIRAC CFC-11 bias-corrected) merged flight ensembles with data from Bonbon and LACE shown for comparison. Panel $a$ : early winter, the solid line is a 1st order regression fit to the early December ensemble, the dashed line is a 1st order regression fit to the late January ensemble (dotted lines are $95 \%$ confidence limits). Panel $b$ : late winter, the solid line is a 1st order regression fit to the late January ensemble, the dashed line is a 1 st order regression fit to the early March ensemble.

From the merged data we diagnose ozone loss throughout the profile for CFC11 mixing ratios less than about $175 \mathrm{pptv}$ (corresponding to about $370 \mathrm{~K}$ ). There is a 1100 ppbv change in ozone at a CFC11 mixing ratio of 50 pptv (about $430 \mathrm{~K}$ ), a 700 ppbv ozone change for 100 pptv CFC11 (about $405 \mathrm{~K}$ ) and a 300 ppbv $\mathrm{O}_{3}$ change for $150 \mathrm{pptv}$ of CFC11 (about $385 \mathrm{~K})$. Note that the bias-correction in the DIRAC data is independent of time during the campaign and so makes no difference to the ozone loss calculation (see Appendix). Also evident from Fig. $6 \mathrm{~b}$ is the excellent agreement in early March between the $\mathrm{O}_{3} / \mathrm{CFC} 11$ relation for the merged data and that from the 1 March Bonbon flight and the 5 March LACE flight.

A SLIMCAT calculation was performed for this winter (1999/2000) and the ozone evolution agreed well with data (Sinnhuber et al., 2000). To investigate ozone change based on SLIMCAT, we calculated ozone loss in several ways. The net ozone loss can be found by summing all the production and loss terms. The loss calculated this way agrees extremely well with loss calculated as the difference between a passive ozone tracer and the modelled ozone (Millard et al., 2002). In addition, for this study we have also calculated the ozone loss by using the $\mathrm{O}_{3} / \mathrm{CFC}-11$ tracer relationship calculated in the model. Thus, the model data for each flight date are grouped into ensembles and treated in the same way as the measurements. For our region of interest at potential temperatures below $500 \mathrm{~K}$, the ozone loss derived in this way from the model fields also agrees extremely well with the loss derived directly by the two other methods described above. Investigations into the possible impact of vortex inhomogeneity on model ozone loss calculations show that the maxi- mum variability in ozone loss along $5^{\circ} \mathrm{PV}$ equivalent latitude bands reached $27 \%$ in mid January 2000 . This ozone loss variability then remained below $18 \%$ from the beginning of February onward, between $440 \mathrm{~K}$ and $500 \mathrm{~K}$ potential temperature (Millard et al., 2002). The low variability in vortex ozone loss makes the use of balloon based measurements as indicators of vortex average ozone loss particularly relevant in this winter. SLIMCAT diagnosed ozone loss rates in 1999/2000 agree well with "Match" diagnosed ozone loss until March 2000. Thereafter, SLIMCAT underestimates the rate of ozone loss by $\sim 2$ ppbv per sunlit hour due to insufficient model denitrification in the presence of large NAT PSCs. We note also that the model may not have reproduced the observed chlorine activation accurately because of a negative temperature bias in the forcing fields; nevertheless, modelled and observed $\mathrm{ClO}$ do compare well at levels below $500 \mathrm{~K}$ which is the region of interest here (Fig. 5). Figure 7 shows the equivalent plots to Fig. 6 for the vertical distributions of $\mathrm{O}_{3}$ and CFC11 from SLIMCAT above Kiruna for the DIRAC/DESCARTES merged flight dates. Little change in the relation is seen between the December 1999 and January 2000 dates, consistent with the observations, but a large shift is again seen between the January and March dates (see also the linear regression data in Table 3b). The SLIMCAT $\mathrm{O}_{3} / \mathrm{CFC} 11$ relation for early March clearly shows the top of the depleted ozone layer in common with the measurements.

Figure 8 shows the altitude distribution of ozone change using the merged data for the period 9 December to 25 January obtained by plotting the ozone difference at fixed CFC11 values against the relevant potential temperatures for the 25 January flight ensemble. Uncertainty estimates (indicated 

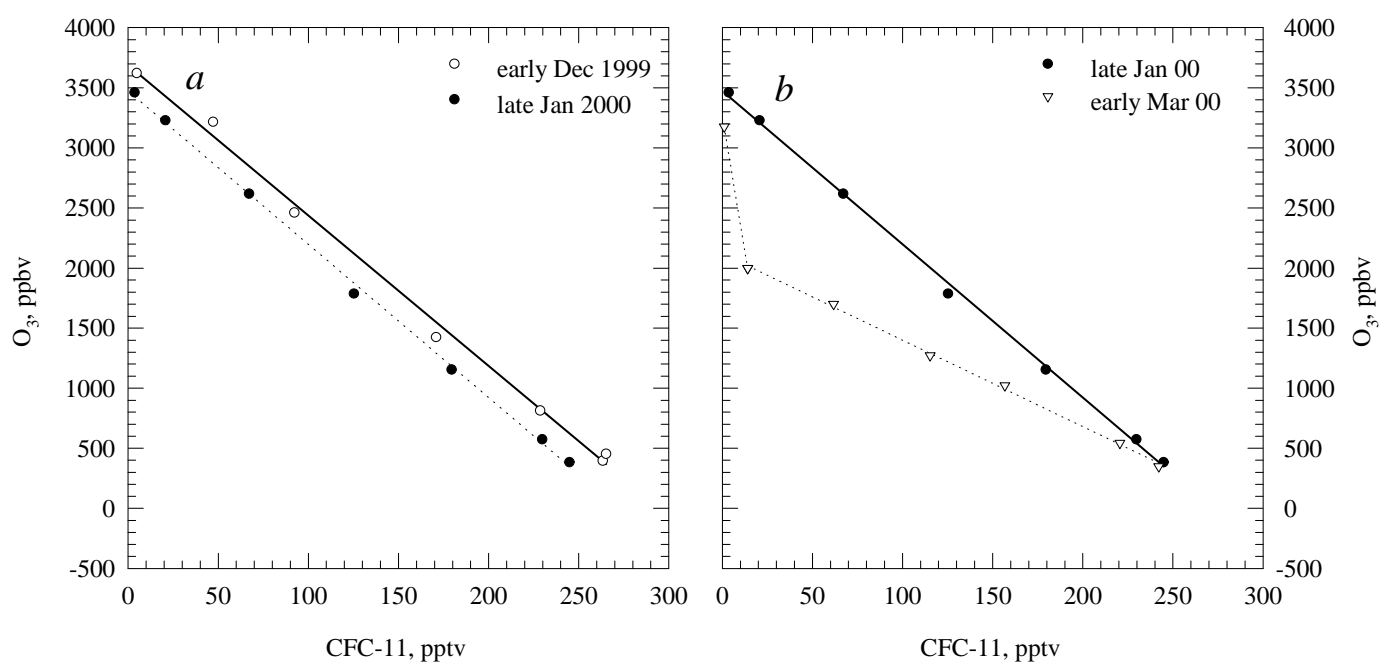

Fig. 7. The relationship between SLIMCAT CFC11 and ozone for the DIRAC/DESCARTES merged flight dates (panel $a$ : early December and late January; panel $b$ : late January and early March). Solid lines are 1st order regression fits to the earlier ensemble in each panel, dashed lines are 1st order regression fits to the later ensemble in each panel. Note: two regression lines are used for the early March ensemble in panel $b$, one through all the points where we diagnose ozone loss and another from the highest ozone loss point to the top of the ozone depleted zone.

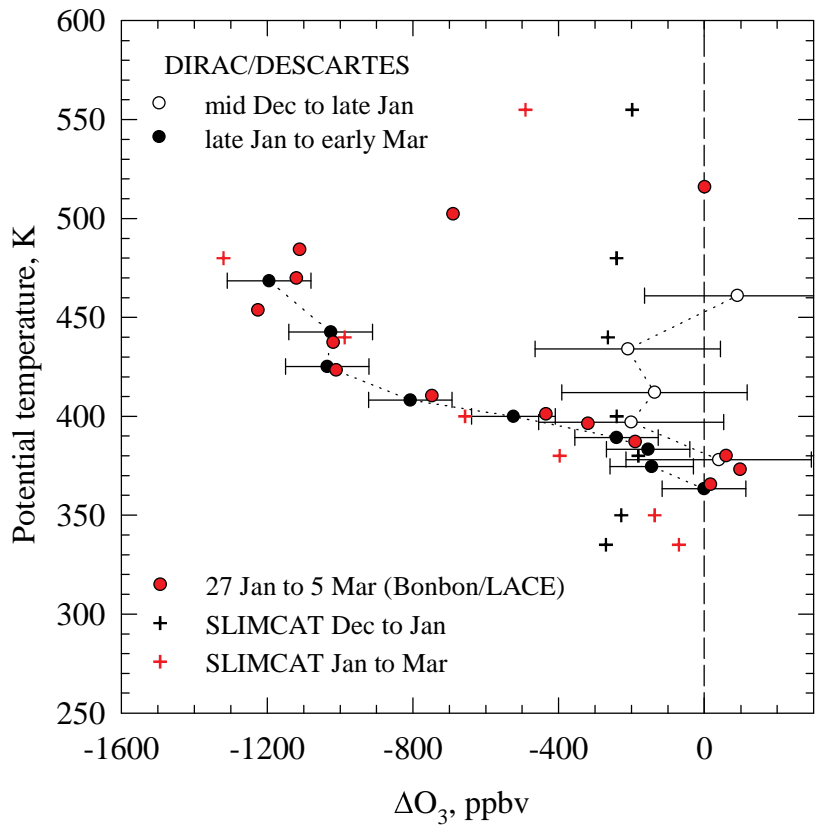

Fig. 8. The vertical distribution of ozone change from early December to late January and from late January to early March derived from the relationships between CFC11 and ozone for the merged DIRAC/DESCARTES flights (DIRAC CFC-11 biascorrected). Also shown is the profile of ozone change between 27 January and 5 March based on the Bonbon and LACE data. The SLIMCAT vertical ozone change (calculated from the model $\mathrm{O}_{3} / \mathrm{CFC}-11$ correlations) is shown for the same periods as the merged DIRAC/DESCARTES ozone change plots. by horizontal bars) are the addition in quadrature of the standard errors for the ozone mixing ratios in the regressions defining the $\mathrm{O}_{3} / \mathrm{CFC} 11$ relations (shown in Fig. 6). The measurements show only a small ozone loss in the $400-450 \mathrm{~K}$ region between December and January. We caution that the error bars on this derived loss are large and preclude any more definitive conclusions regarding the January ozone loss. Also shown in Fig. 8 is the altitudinal ozone change for the period from 25 January to 5 March obtained by plotting the ozone difference for fixed CFC11 values against the potential temperatures for the 5 March flight ensemble. During this period there was substantial ozone loss with a maximum of about $1200 \mathrm{ppbv}$ in the $440-470 \mathrm{~K}$ region with ozone loss to a lesser extent down to about $370 \mathrm{~K}$. Figure 8 also shows the altitude distribution of ozone change using the Bonbon and LACE data for the period 27 January to 5 March calculated using the same methodology as with the DIRAC and DESCARTES data. There is an excellent agreement in both the magnitude and position of the ozone loss maximum and both data sets show ozone loss extending down to the 370 $380 \mathrm{~K}$ region.

The vertical distribution of ozone change based on the SLIMCAT $\mathrm{O}_{3} /$ CFC- 11 correlations was examined for the periods of early December to late January and late January to early March (both using the same dates as the merged DIRAC/DESCARTES data). As with the measurement data, the ozone differences are plotted against the potential temperature of the later flight date for each period. These model ozone change distributions are also shown in Fig. 8 together with the measurements. The model shows slight ozone loss $(<300 \mathrm{ppbv})$ in the $450-550 \mathrm{~K}$ region in the early December 
to late January period. This is reminiscent of the change based on our observations discussed above, but we must emphasise again that the errors here are significant. The model shows a maximum ozone loss of $1300 \mathrm{ppbv}$ at $480 \mathrm{~K}$ for the late January to early March period, very similar to the loss derived from the measurements.

\section{Conclusions}

The ascent data from DIRAC and DESCARTES provide a set of CFC11 profiles from a total of nine balloon flights made during the 1999/2000 Arctic winter. These vertical profiles compare well qualitatively with SLIMCAT CFC11 profiles for the same dates and location. There is good quantitative agreement below $400 \mathrm{~K}$; above this level the model has too weak descent. Observations of $\mathrm{ClO}$ on the 8 March flight are in good agreement with $\mathrm{ClO}$ output for the SLIMCAT model in the region where we derive ozone loss below about $500 \mathrm{~K}$, adding confidence to the model's derived ozone loss in the vortex.

Using ECC ozonesonde data from the balloon flights inside the vortex (or from small balloons launched soon after) changes in the $\mathrm{O}_{3} / \mathrm{CFC} 11$ relationship are observed throughout the winter. Grouping the flights into ensembles and merging the DIRAC and DESCARTES data provides a means of estimating the vertical change in ozone concentration from early December to late January and from late January to early March. SLIMCAT ozone and CFC-11 data generated for the same dates and location as the measurements are grouped into the same ensembles and treated identically to the measurement data. The merged flight ensembles show a very small ozone loss, with large uncertainty, between early December and late January, the model shows slight ozone loss ( $<300 \mathrm{ppbv}$ in the $450-550 \mathrm{~K}$ region). Between late January and early March the merged measurements show a maximum ozone loss of $1200 \mathrm{ppbv}$ in the 440-470 K region which compares excellently with the maximum loss calculated by the model ( $1300 \mathrm{ppbv}$ at $480 \mathrm{~K})$.

A thorough comparison of ozone loss rates requires a detailed examination of the conditions (period, altitude, location) over which the ozone loss occurs (Harris et al., 2002) and is beyond the scope of this study. However simple comparisons with the other studies in the 1999/2000 winter (Hoppel et al., 2002; Klein et al., 2002; Müller et al., 2003 and discussion therein; Rex et al., 2002; Richard et al., 2001; Salawitch et al., 2002; Schoeberl et al., 2002; summary in Table 8 of Newman et al., 2002) show good agreement. We find that the peak loss occurred in the $440-470 \mathrm{~K}$ region, which is the same as Müller et al. (2003), at the low end of the range. Our peak loss of $1200 \mathrm{ppbv}$ is less than those of some other studies (e.g. 2000 ppbv of Rex et al. (2002) and $1800 \mathrm{ppbv}$ of Richard et al. (2001)), but this is at least partly related to the earlier end to the period we consider. The cumulative ozone loss reported by Match on about March 5 (the average date of our March flights) is about 1500 ppbv (Fig. 6 in Rex et al., 2002), within the estimated uncertainties of the two techniques.

Finally, the study shows that in winters when the polar vortex is relatively undisturbed, tracer ozone relationships measured from a single location (and model output also) can be used to provide ozone loss estimates which are in good agreement with the modelled ozone loss for the vortex core as a whole.

\section{Appendix: DIRAC measurement quality}

Here follows a discussion in more detail on the performance of DIRAC during the campaign with particular emphasis on the factors which effect the accuracy, precision and measurement bias. First are listed the effects for which a correction has been applied, followed by a list of effects which cannot be corrected with the housekeeping data available (the instrument which made the flights was lost on a stray balloon on its fifth flight of the campaign and so post-campaign tests could not be performed). At the end of the Appendix is a discussion on the bias correction which we apply to the DIRAC data for the four flights made during this campaign.

\subsection{Instrument effects: data correction applied}

In-flight calibration. All data during the flights were calibrated using in-flight instrument response curves which were generated on the launch pad and also at float. There was almost no significant difference between instrument sensitivity between the launch pad and float calibrations (Fig. 1 of the text) which demonstrates high instrument stability. No intermediate calibrations were performed between ascent samples leading to the assumption that any change in instrument sensitivity was linear with time between the launch pad and float calibrations.

Post campaign calibration. In August 2000 (4 to 5 months after the campaign) we received a NOAA-CMDL calibrated cylinder of Niwot Ridge air. This was compared in our laboratory (using another GC-ECD instrument) to the calibration cylinder which was used to fill the DIRAC onboard calibration gas bottle during the campaign (a synthetic CFC mixture in a nitrogen balance with a nominal CFC-11 mixing ratio of $250 \mathrm{pptv})$. This provided a link to the NOAA-CMDL calibration scale for CFC-11. The estimated uncertainty for CFC-11 in the NOAA-CMDL sample was $1 \%$, and additional uncertainties incurred in comparing this to our working calibration mixture for the campaign brings the measurement accuracy estimate to $2.5 \%$. An assumption here is that that was no change in the mixing ratio of CFC-11 in our campaign calibration gas between its use for the DIRAC flights and the comparison with the NOAA-CMDL cylinder.

Sample delay time. The sample flow rates at high altitude during this campaign were up to 3 times lower than in 
previous DIRAC flights as a result of a new switching valve with an unexpectedly high flow resistance which could not be changed during the campaign. Owing to this lower than expected sample flow, a time correction was applied to account for the time taken for sample air to pass through the inlet manifold to the adsorbent trap. This correction was based on the measured mass flow logged during each sampling phase and an estimate of the total volume of the inlet manifold upstream from the adsorbent trap. Time corrections for samples above $400 \mathrm{~K}$ ranged from 20 to $60 \mathrm{~s}$. An assumption here is that sample air is flushed through the inlet manifold as plug flow (i.e. with no mixing in the sampling line).

\subsection{Instrument effects: no data correction applied}

Non-plug flow effects. As mentioned earlier, the sample time stamps were corrected for the time delay in air entering the inlet and arriving at the adsorbent bed. However, this assumed plug flow and no corrections are made for non-plug flow effects. We think that this problem was encountered during this campaign and was likely caused by dead volume in the system (e.g. in the pump chambers). Low pressure tests with DIRAC-B show that at low sample flow a small but significant fraction of air from lower altitude remains in the dead volume of the sample pathway (DIRAC-A made the SOLVE-THESEO 2000 measurements but was lost on a later flight in the campaign). This impacts on the measurements above $400 \mathrm{~K}$, causing a systematic bias toward higher reported CFC11 values. The implementation of a new pumping system has since minimised this problem on the instrument.

\subsection{Bias corrected DIRAC dataset}

To fully investigate the bias in the DIRAC data from the campaign the CFC-11 measurements were compared to those from the LACE instrument on the 5 March 2000 flight (which flew on the same gondola as DIRAC). The LACE measurements were first interpolated to the DIRAC sampling levels so that a difference plot could be constructed. At altitudes below $400 \mathrm{~K}$ the DIRAC measurements were less than $10 \%$ higher than those from LACE. At $450 \mathrm{~K}$ the DIRAC measurements were a factor 2 higher than LACE and by $475 \mathrm{~K}$ there was a factor 3 difference. A 3 rd degree polynomial fit through the difference plot was then used to make a bias correction for the other three DIRAC flights made during the campaign. As a check on the consistency of the bias correction the bias-corrected DIRAC profile from the 27 January 2000 flight was compared to the data from Bonbon on the same day (this instrument flew $\sim 2 \mathrm{~h}$ before DIRAC). The bias-corrected data was in excellent agreement with that from Bonbon up to $470 \mathrm{~K}$. Note that this bias-corrected DIRAC dataset is used in all figures and for the ozone loss estimates based on the change in the $\mathrm{O}_{3} / \mathrm{CFC}-11$ relations.
In order to examine the effect of the bias in the DIRAC data on the ozone loss estimates we recalculated the ozone change for the two periods of the study using the bias corrected DIRAC data merged with the DESCARTES data. The difference in the profiles of ozone change between the biased and bias-corrected dataset was small $\left(<150 \mathrm{ppb} \mathrm{O}_{3}\right)$ and well within the error of the estimates, so the bias-correction does not influence our estimated ozone loss.

Acknowledgements. We gratefully acknowledge the following for their financial support: the Research DG of the European Commission through the THESEO $\mathrm{O}_{3}$ loss (ENV4-CT97-0510), THESEO-EuroSOLVE (EVK2-CT-1999-00047) and CRUSOE (EVK2-1999-00252, EVK2-CT-2001-20012) projects; the UK Natural Environment Research Council through its UTLS Ozone programme; the NERC UK Universities Global Atmospheric Modelling Programme (UGAMP) and the NERC Centre of Atmospheric Science (NCAS); the UK Department of Environment, Transport and Regions through its Global Atmospheres Division (EPG 1/1/83); and US National Science Foundation. We would also like to acknowledge CNES, Esrange and NASA for provision of the flights we had during SOLVE-THESEO 2000 and W. Brune for his assistance during the OMS in situ flight. Genevieve Millard thanks the EPSRC for a studentship. We thank A. Hauchecorne for provision of MIMOSA PV maps.

Edited by: V. Fomichev

\section{References}

Bauer, R., Engel A., Franken H., Klein, E., Kulessa, G., Schiller, C., Schmidt, U., Borchers, R. and Lee, J.: Monitoring the vertical structure of the arctic polar vortex over northern Scandinavia during EASOE - regular $\mathrm{N}_{2} \mathrm{O}$ profile observations, Geophys. Res. Lett., 21, 1211-1214, 1994.

Bregman, A., Lelieveld, J., van den Broek, M. M. P., Siegmund, P. C., Fischer, H., and Bujok, O.: $\mathrm{N}_{2} \mathrm{O}$ and $\mathrm{O}_{3}$ relationship in the lowermost stratosphere: A diagnostic for mixing processes as represented by a three-dimensional chemistry-transport model, J. Geophys. Res., 105, 17 279-17 290, 2000.

Chipperfield, M. P., Lee, A. M., and Pyle, J. A.: Model calculations of ozone depletion in the Arctic polar vortex for 1991/92 to 1994/95, Geophys. Res. Lett., 23, 559-562, 1996.

Chipperfield, M. P.: Multi-annual simulations with a threedimensional chemical transport model, J. Geophys. Res., 104, 1781-1805, 1999.

Danis, F., Harris, N. R. P., Taylor, W. H., McIntyre, J. D., Simmonds, P. G., and Pyle, J. A.: DESCARTES: A novel lightweight balloon-borne instrument for measurement of halocarbons, Rev. Sci. Instr., 70, 271-280, 2000.

DeMore, W. B., Sander, S. P., Golden, D. M., Hampson, R. F., Kurylo, M. J., Howard, C. J., Ravishankara, A. R., Kolb, C. E., and Molina, M. J.: Chemical kinetics and photochemical data for use in stratospheric modelling, Evaluation 12, JPL Publ., 974, 1997.

Goutail, F., Pommereau, J.-P., Phillips, C., Deniel, C., Sarkissian, A., Lefèvre, F., Kyrö, E., Rummukainen, M., Ericksen, P., Andersen, S., Kaastad-Hoiskar, B.-A., Braathen, G., Dorokhov, V., 
and Khattatov, V.: Depletion of column ozone in the Arctic during the winters 1993-94 and 1994-95, J. Atmos. Chem., 32, 134, 1999.

Guirlet, M., Chipperfield, M. P., Pyle, J. A., Goutail, F., Pommereau, J.-P., and Kyrö, E.: Modelled Arctic ozone depletion in winter 1997/1998 and comparison with previous winters, J. Geophys. Res., 105, 22 185-22 200, 2000.

Harris, N. R. P., Rex, M., Goutail, F., Knudsen, B. M., Manney, G. L., Müller, R., and von der Gathen, P.: Comparison of empirically derived ozone losses in the Arctic vortex, J. Geophys Res., 107 (D20), 8264, doi:10.1029/2001JD000482, 2002.

Hauchecorne, A., Godin, S., Marchand, M., Heese, B., and Souprayen, C.: Quantification of the transport of chemical constituents from the polar vortex to middle latitudes in the lower stratosphere using the high-resolution advection model MIMOSA and effective diffusivity, J. Geophys. Res., 107 (D20), 8289, doi:10.1029/2001JD000491, 2002.

Hoppel, K., Bevilacqua, R., Nedoluha, G., Deniel, C., Lefèvre, F., Lumpe, J., Fromm, M., Randall, C., Rosenfield, J., and Rex, M.: POAM III observations of Arctic ozone loss for the 1999/2000 winter, J. Geophys. Res., 107 (D20), 8262, doi:10.1029/2001JD000476, 2002.

Kawa, S. R., Bevilacqua, R. M., Margitan, J. J., Douglass, A. R., Schoeberl, M. R., Hoppel, K. W., and Sen, B.: Interaction between dynamics and chemistry of ozone in the setup phase of the Northern Hemisphere polar vortex, J. Geophys. Res., 108 (D5), pp. SOL 53-1, CiteID 8310, doi:10.1029/2001JD001527, 2002.

Klein, U., Wohltmann, I., Lindner, K., and Künzi, K. F.: Ozone depletion and chlorine activation in the Arctic winter 1999/2000 observed in Ny-Ålesund, J. Geophys. Res., 107 (D20), 8288, doi:10.1029/2001JD000543, 2002.

Knudsen, B. M., Larsen, N., Mikkelsen, I. S., Morcrette, J.-J., Braathen, G. O., Kyrö, E., Fast, H., Gernandt, H., Kanzawa, H., Nakane, H., Dorokhov, V., Yushkov, V., Hansen, G., Gil, M., and Shearman, R. J.: Ozone depletion in and below the Arctic vortex for 1997, Geophys. Res. Lett., 25, 627-630, 1998.

Lary, D. J. and Pyle, J. A.: Diffuse radiation, twilight and photochemistry, J. Atmos. Chem., 13, 373-392, 1991.

Lucic, D., Harris, N. R. P., Pyle, J. A., and Jones, R. L.: A technique for estimating polar ozone loss: results for the northern 1991/92 winter using EASOE data, J. Atmos. Chem., 34, 365-383, 1999.

Manney, G. L., Froidevaux, L., Santee, M. L., and Waters, J. W.: MLS observations of Arctic ozone loss in 1996/97, Geophys. Res. Lett., 24, 2697-2700, 1997.

Millard, G. A.: Numerical modelling of polar and middle latitude ozone loss, PhD. thesis, University of Cambridge, UK, 2002.

Millard, G. A., Lee, A. M., and Pyle, J. A.: A model study of the connection between polar and mid-latitude ozone loss in the northern hemisphere lower stratosphere, J. Geophys Res., 108, 8323, doi:10.1029/2001JD000899, 2002.

Moore, F. L., Elkins, J. W., Ray, E. A., Dutton, G. S., Dunn, R. E., Fahey, D. W., McLaughlin, R. J., Thompson, T. L., Romashkin, P. A., Hurst, D. F., and Wamsley, P. R.: Balloonborne in situ gas chromatograph for measurements in the troposphere and stratosphere, J. Geophys Res., 103 (D5), 8330, doi:10.1029/2001JD000891, 2003.

Müller, R., Schmidt, U., Engel, A., McKenna, D. S., and Proffitt, M. H.: The $\mathrm{O}_{3} / \mathrm{N}_{2} \mathrm{O}$ relation from balloon-borne observations as a measure of Arctic ozone loss in 1991/92, Q. J. R. Meterol. Soc.,
127, 1389-1412, 2001.

Müller, R., Tilmes, S., Grooß, J.-U., McKenna, D. S., Müller, M., Schmidt, U., Toon, G. C., Stachnik, R. A., Margitan, J. J., Elkins, J. W., Arvelius, J., and Russell III, J.M.: Chlorine activation and chemical ozone loss deduced from HALOE and balloon measurements in the Arctic during the winter of 1999-2000, J. Geophys. Res., 107, 8302, doi:10.1029/2001JD001423, 2002. [printed 108 (D5), 2003].

Newman, P. A., Harris, N. R. P., Adriani, A., Amanatidis, G. T., Anderson, J. G., Braathen, G. O., Brune, W. H., Carslaw, K. S., Craig, M. S., DeCola, P. L., Guirlet, M., Hipskind, R. S., Kurylo, M. J., Kullmann, H., Larsen, N., Megie, G. J., Pommereau, J.-P., Poole, L. R., Schoeberl, M. R., Stroh, F., Toon, O. B., Trepte, C. R., and van Roozendael, M.: An Overview of the SOLVETHESEO 2000 Campaign, J. Geophys Res., 107 (D20), 8259, doi:10.1029/2001JD001303, 2002.

Pierson, J. M., McKinney, K. A., Toohey, D. W., Margitan, J., Schmidt, U., Engel, A., and Newman, P. A.: An investigation of C1O photochemistry in the chemically perturbed Arctic vortex, J. Atmos. Chem., 32, 61-81, 1999.

Pommereau, J.-P. and Piquard, J.: Ozone, nitrogen dioxide and aerosol vertical distributions by UV-visible solar occultation from balloons, Geophys. Res. Lett., 21, 1227-1230, 1994.

Prather, M. J.: Numerical advection by conservation of secondorder moments, J. Geophys. Res., 104, 6671-6681, 1986.

Proffitt, M. H., Margitan, J. J., Kelly, K. K, Lowenstein, M., Podolske, J. R., and Chan, K.: Ozone loss in the Arctic polar vortex inferred from high-altitude aircraft measurements, Nature, 347, 31-36, 1990.

Proffitt, M. H., Aikin, K., Margitan, J. J., Lowenstein, M., Podolske, J. R., Weaver, A., Chan, K. R., Fast, H., and Elkins, J. W.: Ozone loss inside the northern polar vortex during the 1991-1992 winter, Science, 261, 1150-1154, 1993.

Pyle, J. A., Carver, G. D., and Schmidt, U.: Some case studies of chlorine activation during the EASOE campaigns, Geophys. Res. Lett., 21, 1431-1434, 1994.

Ray, E. A., Moore, F. L., Elkins, J. W., Dutton, G. S., Fahey, D. W., Vömel, H., Oltmans, S. J., and Rosenlof, K. H.: Transport into the NH lowermost stratosphere revealed by in situ tracer measurements, J. Geophys. Res., 104, 26 565-26 580, 1999.

Ray, E. A., Moore, F. L., Elkins, J. W., Hurst, D. F., Romashkin, P. A., Dutton, G. S., and Fahey, D. W.: Descent and mixing in the 1999-2000 northern polar vortex inferred from in situ tracer measurements, J. Geophys. Res., 107 (D20), 8285, doi:10.1029/2001JD000961, 2002.

Rex, M., von der Gathen, P., Braathen, G. O., Reid, S. J., Harris, N. R. P., Chipperfield, M., Reimer, E., Beck, A., Alfier, R., KrugerCarstensen, R., De Backer, H., Balis, D., Zerefos, C., O'Connor, F., Dier, H., Dorokhov, V., Fast, H., Gamma, A., Gil, M., Kyrö, E., Rummukainen, M., Litynska, Z., Mikkelsen, I. S., Molyneux, M., and Murphy, G.: Chemical ozone loss in the Arctic winter 1994/95 as determined by the match technique, J. Atmos. Chem., 32, 35-39, 1999.

Rex, M., Salawitch, R. J., Harris, N. R. P., von der Gathen, P., Braathen, G. O., Schulz, A., Deckelmann, H., Chipperfield, M., Sinnhuber, B.-M., Reimer, E., Alfier, R., Bevilacqua, R., Hoppel, K., Fromm, M., Lumpe, J., Küllmann, H., Kleinböhl, A., Bremer, H., von König, M., Künzi, K., Toohey, D., Vömel, H., Richard, E., Aikin, K., Jost, H., Greenblatt, J. B., Loewen- 
stein, M., Podolske, J. R., Webster, C. R., Flesch, G. J., Scott, D. C., Herman, R. L., Elkins, J. W., Ray, E. A., Moore, F. L., Hurst, D. F., Romashkin, P., Toon, G. C., Sen, B., Margitan, J. J., Wennberg, P., Neuber, R., Allart, M., Bojkov, B. R., Claude, H., Davies, J., Davies, W., De Backer, H., Dier, H., Dorokhov, V., Fast, H., Kondo, Y., Kyrö, E., Litynska, Z., Mikkelsen, I. S., Molyneux, M. J., Moran, E., Nagai, T., Nakane, H., Parrondo, C., Ravegnani, F., Skrivankova, P., Viatte, P., and Yushkov, V.: Chemical depletion of Arctic ozone in winter 1999/2000, J. Geophys Res., 107 (D20), 8276, doi:10.1029/2001JD000533, 2002.

Richard, E. C., Aikin, K., Andrews, A. E., Daube Jr., B. C., Gerbig, C., Wofsy, S. C., Romanshkin, P. A., Hurst, D. F., Ray, E. A., Moore, F. L., Elkins, J. W., Deshler, T., and Toon, G. C.: Severe chemical ozone loss inside the Arctic polar vortex during winter 1999-2000 inferred from in situ airborne measurements, Geophys. Res. Lett., 28, 2197-2200, 2001.

Robinson, A. D., McIntyre, J., Harris, N. R. P., Pyle, J. A., Simmonds, P. G., and Danis, F.: A lightweight balloon-borne gas chromatograph for in situ measurements of atmospheric halocarbons, Rev. Sci. Instr., 71, 4553-4560, 2000.

Salawitch, R. J., Margitan, J. J., Sen, B., Toon, G. C., Osterman, G. B., Rex, M., Elkins, J. W., Ray, E. A., Moore, F. L., Hurst, D. F., Romashkin, P. A., Bevilacqua, R. M., Hoppel, K. W., Richard, E. C., and Bui, T. P.: Chemical Loss of Ozone during the Arctic Winter of 1999-2000: An Analysis Based on Balloon-Borne Observations, J. Geophys Res., 107 (D20), 8269, doi:10.1029/2001JD000620, 2002.

Schoeberl, M. R., Proffitt, M. H., Kelly, K. K., Lait, L. R., Newman, P. A., Rosenfield, J. E., Lowenstein, M., Podolske, J. R., Strahan, S. E., and Chan, K. R.: Stratospheric constituent trends from ER2 profile data, Geophys. Res. Lett., 17, 469-427, 1990.

Schoeberl, M. R., Newman, P. A., Lait, L. R., McGee, T., Burris, J., Browell, E. V., Grant, W., Richard, E., von der Gathen, P., Bevilacqua, R., and Mikkelsen, I. S.: An assessment of the ozone loss during the 1999-2000 SOLVE Arctic campaign, J. Geophys. Res., 107 (D20), 8261, doi:10.1029/2001JD000412., 2002.
Schmidt, U., Bauer, R., Khedim, A., Klein, E., Kulessa, G., and Schiller, C.: Profile observations of long lived trace gases in the Arctic vortex, Geophys. Res. Lett., 18, 767-770, 1991.

Shine, K. P.: The middle atmosphere in the absence of dynamical heat fluxes, Q. J. R. Meteorol. Soc., 113, 603-633, 1987.

Sinnhuber, B. M., Chipperfield, M. P., Davies, S., Burrows, J. P., Eichmann, K. U., Weber, M., von der Gathen, P., Guirlet, M., Cahill, G. A., Lee, A. M., and Pyle, J. A.: Large loss of total ozone during the Arctic winter of 1999/2000, Geophys. Res. Lett., 27, 3473-3476, 2000.

Solomon, P., Barrett, J., Conner, B., Zoonematkermani, S., Parrish, A., Lee, A., Pyle, J. A., and Chipperfield, M.: Seasonal observations of chlorine monoxide in the stratosphere over Antarctica during the 1996-1998 ozone holes and comparison with the SLIMCAT 3D model, J. Geophys. Res., 105, 28 979-29001, 2000.

Swinbank, R. and O'Neill, A.: A stratosphere-troposphere data assimilation system, Mon. Weather Rev., 122, 686-702, 1994.

Vogel, B., Müller, R., Deshler, T., Grooß, J.-U., Karhu, J., McKenna, D. S., Müller, M., Toohey, D., Toon, G. C., and Stroh, F.: Vertical profiles of activated $\mathrm{ClO}$ and ozone loss in the Arctic vortex in January and March 2000: In situ observations and model simulations, J. Geophys. Res., 108 (D22), 8334, doi:10.1029/2002JD002564, 2003.

Vömel, H., Toohey, D. W., Deshler, T., and Kröger, C.: Sunset observations of $\mathrm{ClO}$ in the arctic polar vortex and implications for ozone loss, Geophys. Res. Lett., 28(22), 4183-4186, 10.1029/2001GL013413, 2001.

Waugh, D. W., Plumb, R. A., Elkins, J. W., Fahey, D. W., Boering, K. A., Dutton, G. S., Volk, C. M., Keim, E., Gao, R. S., Daube, B. C., Wofsy, S. C., Loewenstein, M., Podolske, J. R., Chan, K. R., Proffitt, M. H., Kelly, K., Newman, P. A., and Lait, L. R.: Mixing of polar vortex air into middle latitudes as revealed by tracer-tracer scatterplots, J. Geophys. Res., 102, 13 119-13 134, 1997. 